\title{
Parental Deprivation Induces N-Methyl-D-Aspartate-Receptor Upregulation in Limbic Brain Areas of Octodon degus: Protective Role of the Maternal Call
}

\author{
Irina Ziabreva, Reinhild Schnabel, and Katharina Braun ${ }^{\dagger}$ \\ Leibniz Institute for Neurobiolology and Department of Zoology/Developmental \\ Neurobiology at the Otto von Guericke University, P.O. Box 1860, 39008 Magdeburg, \\ Brenneckestr. 6, D-39118 Magdeburg, Germany
}

\section{SUMMARY}

An optimal coordination between parents and their offspring involves a sequence of reciprocal behaviors to ensure the adequate care of the young, which is critical for a healthy physical, emotional, and social development. Parental deprivation, particularly an impaired child-mother attachment, induces lasting changes in emotional as well as in cognitive capacities in later life. We assessed in the South American precocial species, Octodon degus, whether alterations of glutamatergic function of the limbic system induced by parental deprivation may be a neural correlate for such behavioral changes. Further, we analyzed whether the mother's voice can protect from separation-induced changes of brain function. Changes of N-methyl-D-aspartate (NMDA) receptor expression were examined in the following three groups of 2-week-old Octodon degus pups: (I) control animals who remained undisturbed with the family; (II) animals who were repeatedly separated from the family and individually placed in an unfamiliar environment for behavioral analysis (open field); and (III) animals who were treated like the group described under (II) but were presented with maternal vocalizations during separation. Relative to those in the control group I, the animals in group II showed an upregulation of NMDA receptor density in the (a) anterior cingulate, prelimbic, infralimbic, and anterior insular cortices; (b) CA1/stratum radiatum; (c) CA1/stratum lacunosum moleculare and CA3/stratum radiatum; and (d) in the basomedial amygdaloid nucleus. Presentation of the maternal call during the separation period (group III) suppressed the separation-induced NMDA receptor upregulation in all regions. The results demonstrate that early life events can influence the expression of transmitter receptors and that maternal behavior, acting to control the pup's socio-emotional environment, is a key factor for regulating such developmental events.

\section{INTRODUCTION}

In sensory system development, genetically preprogrammed neuronal plasticity is highly sensitive to environmental stimulation. This experience-regulated plasticity, on the one hand, is

\footnotetext{
${ }^{\dagger}$ Corresponding author:

tel: +493916263617 ; fax: +493916263618

e-mail: braun@ifn-magdeburg.de
} 
beneficial for an adaptive and appropriate functional development of brain pathways. On the other hand, such plasticity can be detrimental because of the brain's high vulnerability toward early adverse environ-mental conditions, which can lead to the abnormal development of both brain and behavior. Quite analogous to the impaired functional maturation of the sensory systems after sensory deprivation, either early socio-emotional deprivation or adverse, stressful emotional experiences may induce an impaired or altered development of the limbic pathways. Such functional deficits in the limbic system may be the neural correlate of behavioral disturbances and cognitive and emotional deficits, which are typically observed in socially deprived animals and humans (Hall, 1998; Suomi, 1991; Spitz, 1945; Gray, 1958; Skeels, 1966). The neural mechanisms underlying such early developmental disturbances, however, are not well understood.

For the newborn individual, one of the most stressful and fear-inducing experiences is separation from the parents and exposure to an unfamiliar environment. This experimentally easily inducible and well-controlled paradigm provides an ideal model for the investigation of deprivation- and experience-regulated brain development. Studies in this animal model revealed a variety of changes in the composition of different transmitter systems, including the monoaminergic and nitric oxide systems (Braun et al., 2000; Poeggel et al., 1999; 2000; Thoa et al., 1976; Weinstock et al., 1978; Jones et al., 1992), but only a few studies analyzing changes on the receptor level have been performed (Liu et al., 2000). As glutamate is the most dominant excitatory transmitter in the brain and because its NMDA receptor subtype is not only involved in learning but also plays a role during brain development, we investigated whether repeated brief separation from the parents during the first weeks of life-namely, a period during which the pups are still highly dependent on parental care-changes the density of NMDA receptors in limbic brain regions. NMDA receptors are involved in the brain's response to environmental cues (Lil-Jequist et al., 1993) and are activated by stressful events (Shors \& Mathew, 1998), including the expression of anxiety that is induced by maternal separation (Kehne et al., 1991). NMDA receptors participate in processes of juvenile and adult learning (Hattori et al., 1990; Flood \& Morley, 1998, Bock et al., 1996, 1997; Roullet et al., 1999), brain maturation (Hattori \& Wasterlain, 1990), neuronal plasticity (Staubli, 1995; Bock \& Braun, 1999), and formation of spatial memory (Izquierdo \& Medina, 1997; Guitierrez et al., 1999). They also play a role in the pathogenesis of a variety of diseases, including epilepsy (Musshoff et al., 2000; Folbergrova et al., 2000; Mikuni et al., 1999), Parkinson's disease (Blandini et al., 1996), and schizophrenia (Olney et al., 1999; Olney \& Farber, 1995).

A further aim of this study was to investigate the regulatory role of maternal behavior-in particular vocal communication with her offspringon deprivation-induced receptor changes. For studying the role of maternal vocalizations on the pup's motivational and emotional status at the behavioral level and in relation to early postnatal brain development, the Octodon degus-a South American precocial species formerly classified as a caviomorph rodent but now considered to belong to lagomorpha (rabbits)-offers certain unique advantages. Most remarkable is that both parents engage equally in the care of their offspring (Wilson, 1982). Unlike rats and mice, degu pups are born with functional sensory systems, and this relative maturity of the sensory systems allows the newborn pups, like human newborns, to perceive and to respond to familiar and novel stimuli, including con-specific vocalizations, immediately after birth. The species is characterized by a highly elaborated vocal repertoire, which is used for communication among parents, offspring, and other 
group members (Fulk, 1976). The newborn pups must learn to recognize and to respond to the mother's vocalizations within the first days of life (Poeggel \& Braun, 1996; Braun \& Scheich, 1997), which is analogous to behavior observed in human babies (De Casper \& Fifer, 1980).

\section{EXPERIMENTAL PROCEDURES}

All experiments were performed in accordance with the European Communities Council Directive of November 1986 (86/609/EEC), and all efforts were made to minimize both the suffering and the number of animals used in the present study.

The degus used in this study were bred in our colony. Family groups consisting of an adult couple and their offspring were housed in standard rat cages (length $\times$ height $\times$ depth: $53 \times 24 \times 32 \mathrm{~cm}$ ). The animals were exposed to an artificial light/ dark cycle with $12 \mathrm{~h}$ lights on. Fresh drinking water and rat diet pellets, vegetables, and fruit were available ad libitum. The animal rooms were air conditioned, with an average temperature of $22^{\circ} \mathrm{C}$.

\section{Behavioral experiments}

The behavioral experiments were intended to give a rough estimate of the pup's behavior during the separation period and to test if maternal vocalizations have any effect on their behavior. The pups remained undisturbed with their families until postnatal day $7(\mathrm{P} 7$; day of birth $=\mathrm{P} 0)$. On P8, an analysis of exploratory activities during parental separation in an unfamiliar environment (size of the open field: $70 \times 70 \times 24.5 \mathrm{~cm}$ ) was started in the following two experimental animal groups:

- Short parental separation (SPS): Animals (14 males, 17 females) were individually placed into the open field arena. This procedure, which induces a brief separation from parents and siblings and exposure to a novel environment, was performed twice daily for 3 min each session, starting at $\mathrm{P} 8$ and continuing through P10, resulting in a total of 6 parental separation sessions and a total parental separation time of $18 \mathrm{~min}$.

- Short parental separation + tone $(\mathrm{SPS}+\mathrm{T})$ : Animals (18 males, 13 females) were treated like those in the SPS group, but a maternal call (= tone) was presented during the $3 \mathrm{~min}$ of parental separation in the open field. For details of the acoustic features of the maternal call, see (Poeggel \& Braun, 1996; Braun \& Scheich, 1997).

- Normal (NORM): Age-matched animals (5 males, 8 females), who had been raised under socially undisturbed conditions with their families, served as a control group for the receptor autoradiography experiments (Fig. 1).

Locomotor activity was analyzed as running activity in $\mathrm{cm} / 3 \mathrm{~min}$ separation. The age for the deprivation procedure and the time of brain analysis were chosen from previous studies showing that by P8, degus pups have developed a clear behavioral response toward the maternal call (Poeggel \& Braun, 1996; Braun \& Scheich, 1997).

\section{Ligand autoradiography}

For the autoradiographic analysis, 14-day-old animals from the SPS ( 5 males, 6 females) and SPS+T ( 6 males, 6 females) groups were used. On P14, the animals of groups NORM, SPS, and SPS+T were decapitated, and the brains were removed from the skull and frozen at $-80^{\circ} \mathrm{C}$. Series of $10 \mu \mathrm{m}$ thick sections were cut on a cryostat (Micron, Dortmund, Germany), mounted on gelatincoated slides, and stored at $-20^{\circ} \mathrm{C}$ until use.

The method for incubation was performed as described in Schnabel and Braun (1996). In the present study, we applied a saturable ligand 


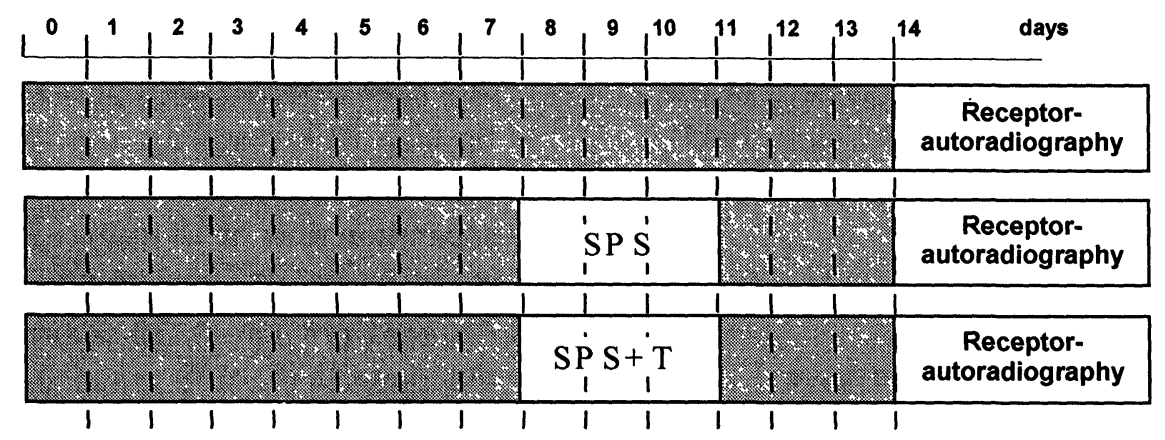

Fig. 1: Experimental procedure for brief parental deprivation and exposure to a novel environment (Open field) with (SPS+T $=$ short parental separation + tone) and without $(\mathbf{S P S}=$ short parental separation) presentation of maternal vocalization.

concentration to analyze maximal binding to the receptor. The sections of all three animal groups were processed simultaneously.

After preincubating for $30 \mathrm{~min}$ in the incubation buffer, the sections were incubated for another $2 \mathrm{~h}$ with $20 \mathrm{nM}\left[{ }^{3} \mathrm{H}\right]-\mathrm{MK} 801$ (NEN, Köln, Germany) $(30 \mathrm{Ci} / \mathrm{mmol})$ in $50 \mathrm{mM}$ Tris $-\mathrm{HCl}$ at room temperature. Nonspecific binding was determined by a parallel incubation in the presence of $100 \mathrm{nM}$ MK801. Incubation was terminated by rinsing the sections three times for $10 \mathrm{~min}$ each in ice-cold buffer, after which they were briefly dipped in cold distilled water and dried in a steam of cold air. For quantitative analysis, slides of all three groups, together with tritium standards (Biotrend, Köln, Germany), were exposed for $6 \mathrm{~d}$ to imaging plates (Fuji, Japan). The resulting radiation images on the imaging plates were read by the scanner unit of the imaging system BAS3000 (Fuji). The photostimulated luminescence (PSL) was measured in each measuring field (integrated PSL over the area) of the brain and in the tritium standards, the background was subtracted, and the resulting PSL was calculated per $\mathrm{mm}^{2}$ using TINA2.9 software (Raytest, Straubenhardt, Germany).

For each animal and each brain region, six sections over a rostro-caudal extension of $250 \mu \mathrm{m}$ were measured; after subtracting the background intensity, we calculated the mean labeling densities for each brain region. Brain regions were selected for quantitative analysis according to their distinct labeling and clear identification from adjacent areas.

The following brain regions were analyzed (Fig. 2):

1. PFC subregions:

a) anterior cingulate cortex

b) precentral medial cortex

c) pre- and infra-limbic cortex

d) anterior insular cortex.

2. Hippocampus:

e) CA1/stratum radiatum

f) $\mathrm{CA} 1 /$ stratum lacunosum moleculare

g) $\mathrm{CA} 3 /$ stratum radiatum.

3. Amygdala:

h) basomedial amygdaloid nucleus.

To test for gender specific variations and for hemispheric asymmetries, we carried out separately all quantitative analyses for male and female pups and for right and left hemispheres, respectively.

Receptor densities were calculated as molar quantities of the bound radioligand per unit protein (fmol/mg) by calibrating the measured $\mathrm{PSL} / \mathrm{mm}^{2}$ against tritium standards (Biotrend, Köln, Germany) 

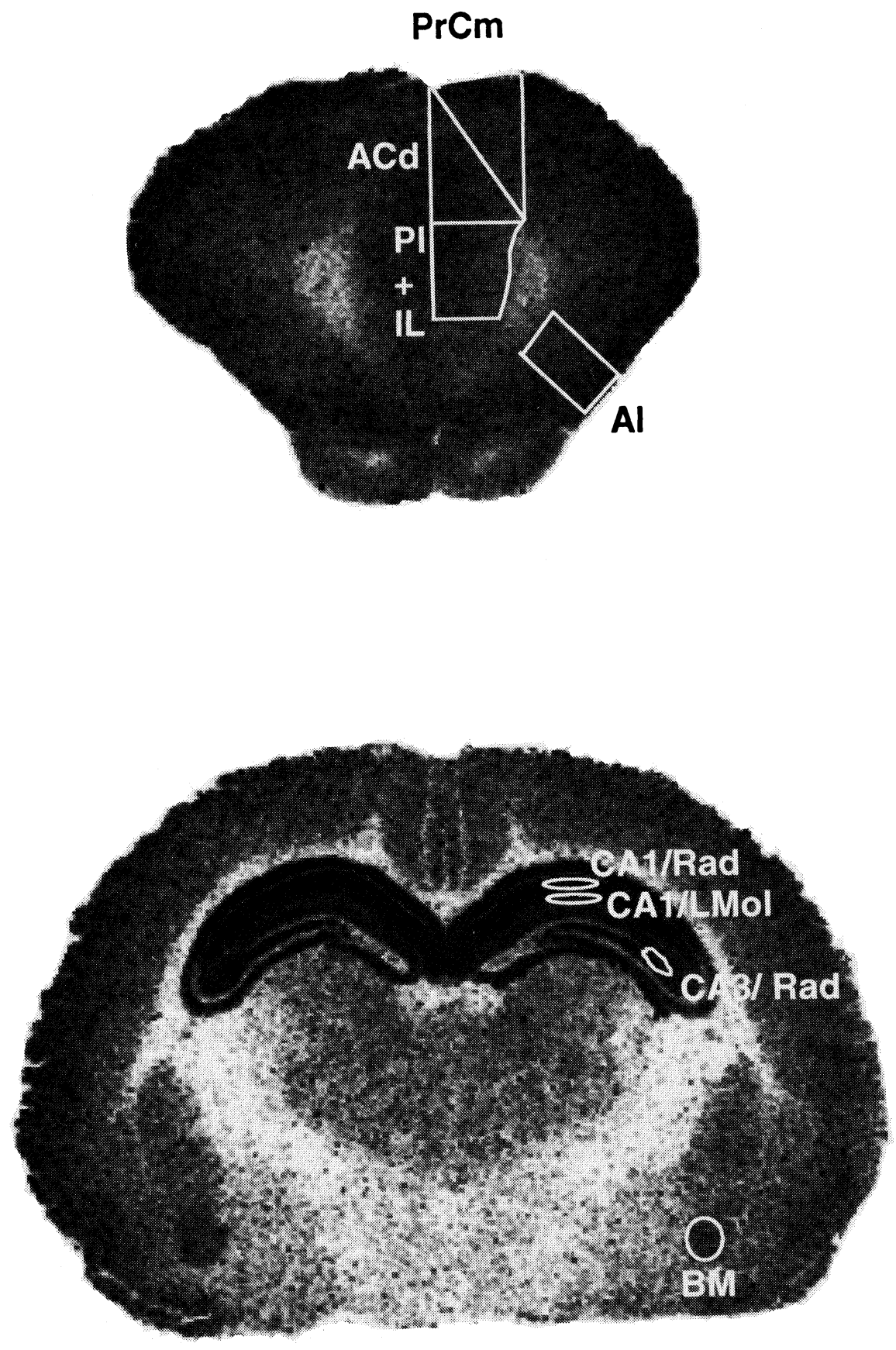

Fig. 2: Topographic localization of NMDA receptors in the forebrain of 2-wk-old Octodon degus demonstrated by binding to the antagonist $\left[{ }^{3} \mathrm{H}\right]-\mathrm{MK} 801$. Frontal sections of anterior (top) and more posterior (bottom) levels of the forebrain. In the outlined areas, receptor densities were quantified using densitometric image analysis.

PrCm, precentral medial cortex; ACd, anterior cingulate cortex; PL+IL, pre- and infra-limbiccortex; AI, anterior insular cortex; $\mathrm{CA} 1 / \mathrm{Rad}$, stratum radiatum of $\mathrm{CA} 1$; $\mathrm{CA} 1 / \mathrm{LMol}$, stratum lacunosum moleculare of $\mathrm{CA} 1$; $\mathrm{CA} 3 / \mathrm{Rad}$, stratum radiatum of $\mathrm{CA} 3$; BM, basomedial amygdaloid nucleus. 
TABLE 1

Locomotor activity during short-term parental deprivation in the open field with and without presentation of parental vocalizations in the first experimental day ( $1+2$ trials)

\begin{tabular}{|c|c|c|}
\hline \multicolumn{2}{|c|}{ Distance run (cm) } & p value \\
\hline SPS $^{\dagger}$ & SPS+T & \\
\hline $495.94 \pm 22.67$ & $374.24 \pm 33.47$ & 0.005 \\
\hline
\end{tabular}

${ }^{\dagger}$ number of animals $=31$; SPS $=$ short parental separation; SMS $+\mathrm{T}=$ short parental separation and parental vocalization; $n=$ number of animals. Values are mean \pm standard error in $\mathrm{fmol} / \mathrm{mg}$. The significance of differences between means was determined with Mann-Whitney U-test; $p$ values are for the SPS group compared with the SPS+T group.

as $\mathrm{nCi} / \mathrm{mg}$, which were then converted into $\mathrm{fmol} /$ $\mathrm{mg}$. The behavioral data and receptor-ligand binding (bound ligand per unit protein) were first analyzed by the Kruskal-Wallis ANOVA, when $\mathrm{p} \leq 0.05$ a pairwise comparison was made using the twotailed Mann-Whitney $U$-test.

\section{RESULTS}

\section{Behavior}

No difference in locomotor activity was found between male and female pups in both behavioral test paradigms, therefore the data for both genders were pooled. The presentation of parental vocalizations (SPS+T group) significantly reduced the running activity during short-term parental separation, but only during the first two periods on the first experimental day (Table 1).

\section{Ligand autoradiography}

In the medial prefrontal cortex (mPFC), the highest level of NMDA-receptor density was detected in the upper cortical layers, as compared with the middle and deeper layers (see Fig. 2). No differences were found between the measured subregions of the mPFC with respect to their NMDA receptor density. As no gender differences and hemispheric asymmetries were observed in any investigated group, the values were pooled.

After short-term parental separation in a novel environment (SPS group), a significant increase of NMDA-receptor density was measured in the anterior cingulate, pre- and infra-limbic, and precentral medial cortices as compared with the NORM control group. In the SMS group, the anterior insular cortex showed a similar but nonsignificant trend toward increased NMDA receptor density (Fig. 3). With regard to NMDAreceptor density, animals that were exposed to parental vocalizations during parental separation (SPS+T group) did not differ from animals of the NORM control group. Except for the anterior insular cortex, in all analyzed $\mathrm{mPFC}$ regions, the animals of the SPS+T group displayed significantly lower NMDA-receptor densities when compared with those of the SPS group (Fig. 3).

In all measured hippocampal regions, the animals from the SPS group showed a clear 

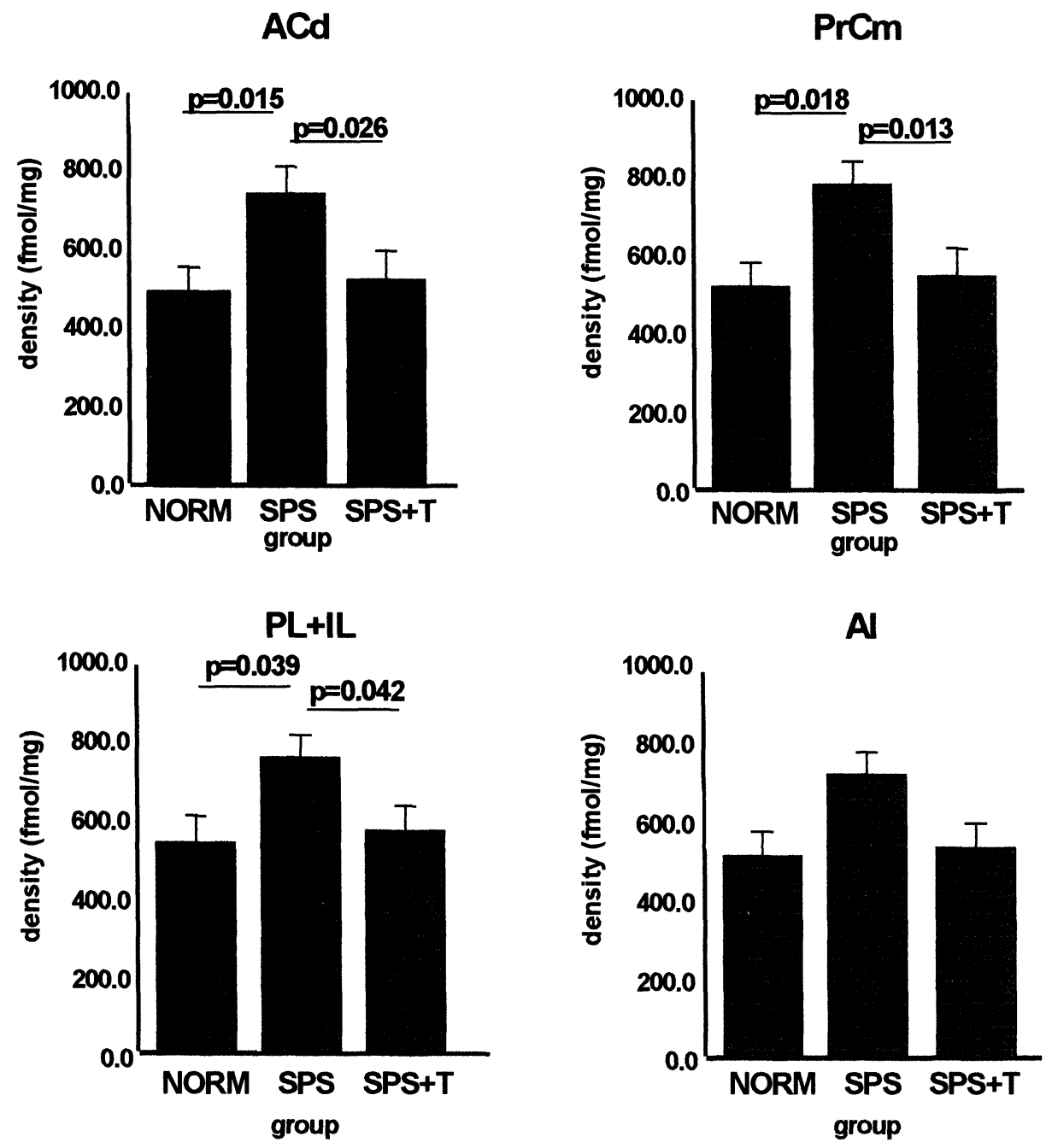

Fig. 3: Medial prefrontal cortex: Changes of NMDA-receptor density after brief parental deprivation and exposure to a novel environment (open field) with (SPS+T = short parental separation + tone) and without (SPS = short parental separation) presentation of parental vocalization. PrCM, precentral medial cortex; ACd, anterior cingulate cortex; PL+IL, pre- and infra-limbic cortex; AI, anterior insular cortex.

increase of NMDA-receptor density compared with that in the NORM group, which was significant for $\mathrm{CA} 1 /$ stratum lacunosum moleculare and $\mathrm{CA} 3 /$ stratum radiatum, but not for $\mathrm{CA} 1 /$ stratum radiatum (Fig. 4). Similar to that in the cortical regions, the NMDA-receptor density of the SPS+T group did not differ from that of the NORM control animals in all measured hippo- campal regions. The presentation of the parental call (SPS+T group) significantly suppressed NMDA-receptor upregulation in the CA1/stratum lacunosum moleculare and the CA3/ stratum radiatum hippocampal regions (Fig. 4). In the CA1/stratum radiatum, a similar suppressive effect of the parental call was observed but did not reach significant values. 
CA1/ stratum radiatum

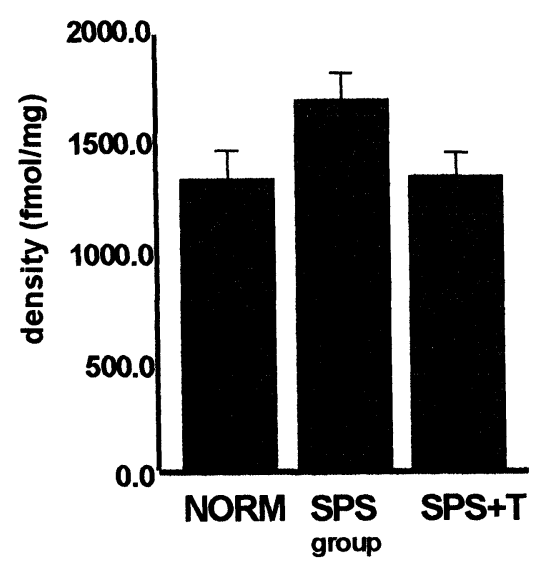

$\mathrm{CA} 3$ / stratum radiatum

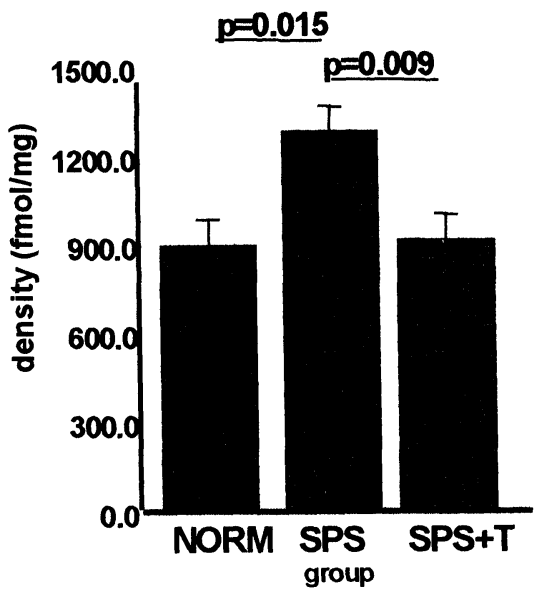

CA1/ stratum lacunosum moleculare

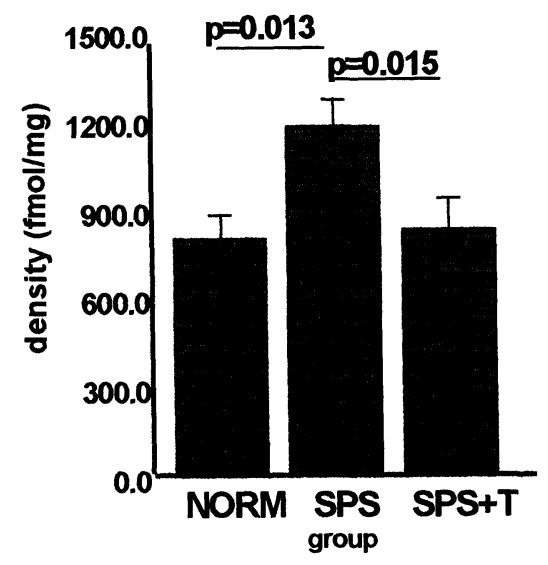

basomedial amygdaloid nucleus

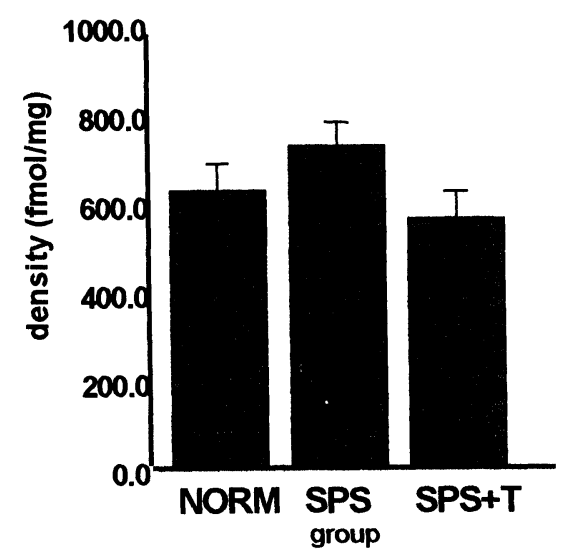

Fig. 4: Hippocampus and amygdala: Changes of NMDA-receptor density after brief parental deprivation and exposure to a novel environment (open field) with (SPS+T $=$ short parental separation + tone) and without (SPS $=$ short parental separation) presentation of parental vocalization. Values are mean \pm standard error.

In the basomedial amygdaloid nucleus, the differences observed among the three groups showed the same trend as those for the other brain areas, but these differences did not reach statistical significance (Fig. 4).

\section{DISCUSSION}

The results of the present study in 2-wk-old Octodon degus pups demonstrate that repeated, brief changes of the socio-emotional environment can alter glutamatergic function in the juvenile brain. An increase of NMDA receptor density in limbic brain areas was observed 3 days after 6 episodes of brief parental deprivation and exposure to an unfamiliar environment. This upregulation was suppressed by the acoustic presence of the mother (parental vocalizations) during the separation period. The behavioral observations revealed a suppressive effect of parental vocalizations on exploratory activity, most likely 
through its 'anxiolytic' effect, namely, by reducing the pup's fear.

A mother's voice is an intense acoustic signal that can already be measured in the amniotic environment; it has both acute and enduring effects on the development of the brain, as well as on later emotional development (Fifer \& Moon, 1994). Parental vocalizations can be regarded as a powerful emotional signal, which in many species, including humans, is an essential part for the establishment and maintenance of the child-mother attachment. Parental vocal communication regulates the pup's physical development (Poeggel \& Braun, 1996, Braun \& Scheich, 1997) and behavior, most likely by protecting the pup from exposure to frightening situations and by reducing its level of anxiety during stressful experiences. Previous research showed that during the first postnatal week, Octodon degus pups learn the meaning (including its emotional context) of the 'mothering call', which is used by the dams specifically during nursing episodes (Poeggel \& Braun, 1996; Braun \& Scheich, 1997), and that these vocalizations evoke strong approach behavior in the young pups. On the behavioral level, this fearreducing function of the mother's voice is further documented in the present study in the downregulation of running activity, which occurred only during the first two episodes of parental deprivation-namely, when the pups still felt insecure in an unfamiliar situation, but not after they had habituated (trials four to six). On the brain systems level, the finding that the mere acoustic presence of the mother (the 'mothering call') is already sufficient to 'buffer' the stress/ anxiety-induced NMDA receptor upregulation in the limbic system may also be related to the 'anxiolytic' effect of parental vocalizations.

Assuming the 'anxiolytic' effect of parental vocalization on behavior and brain function, the main contributing factors to the NMDA receptor upregulation appear to be stress and anxiety during the separation period. A participation of NMDA receptor activation in emotional stress during parental separation has been shown in pharmacological behavioral experiments in pups of laboratory rats, in which the application of NMDA receptor antagonists suppressed ultrasonic vocalizations which represent a reliable indicator for fear and anxiety (Kehne et al., 1991). The few studies done in very young animals demonstrate that the juvenile brain is sensitive to stressful experiences and is capable of changing its transmitter receptors in response. In adult rodents, changes of glutamatergic receptor subtypes have been observed in a variety of stress paradigms (Akinci \& Johnson, 1993; Bartanusz et al., 1995; Krugers et al., 1993). Furthermore, it has been reported that the activation of NMDA receptors participates in responses to stressful situations (Shors \& Mathew, 1998; McEwen, 1999) by stimulating pituitary hormone release (Jezova et al., 1995; Zelena et al., 1999) and the synthesis and release of dopamine within the striatum, hippocampus, substantia nigra (Doherty \& Gratton, 1997; Zigmond et al., 1998), ventral tegmental area, and PFC (Jedema \& Moghaddam, 1994; Takahata \& Moghaddam, 1998). An increase of AMPA but not of NMDA receptors has been found after $1 \mathrm{~h}$ of acute immobilization/shock stress (Tocco et al., 1991); after repeated immobilization stress, levels of GluR1 mRNA were elevated in the hippocampus (Schwendt \& Jezova, 2000), whereas social stress induced a decrease of AMPA receptors (Krugers et al., 1993).

It is still unclear whether these environmentally induced transmitter changes are adaptive and beneficial for the animal's coping with future psychocoscial challenges or whether they are detrimental and impair the animal's tolerance toward novel and stressful fear-inducing stimuli. Upregulation of NMDA receptor density occurs in limbic structures, such as the hippocampus and medial prefrontal cortex, and with a weaker 
response also in the amygdala-regions that are involved in the perception of emotional signals and in the regulation of behavioral responses. In adult rodents, the activation of NMDA receptors has been shown to be responsible for stressinduced alterations of LTP and LTD and appears to mediate stress-induced neuronal atrophy in the hippocampus (McEwen \& Magarinos, 1997). In our juvenile animals, most brain areas that are involved in emotional perception and behaviorsuch as the anterior cingulate cortex with its reciprocal connections to the amygdala, a central fear system that is involved in both the expression and acquisition of conditioned fear (LeDoux, 1998; Staubli, 1995), and the hippocampus as a structure involved in learning and memory formation-showed altered NMDA receptor densities, which could transiently or permanently alter the animals responsiveness and behavioral strategies toward changes in the social environment. These observations-together with our finding that, at least in juvenile animals, transmitter receptors can rapidly change during and after exposure to a behavioral test procedure-should be considered whenever behavioral test series are designed. One should be aware that the first behavioral trial may already alter the biochemical composition of the brain and thereby influence the animal's performance in subsequent trials.

The NMDA receptor upregulation was still measurable 4 days after the last episode of parental separation, suggesting that the receptor changes may persist during the pre- and post-weaning periods and perhaps even until adulthood, but this topic requires further investigation. More-over, it remains to be analyzed if and in which way transient or lasting abnormally high NMDA receptor densities during critical phases of postnatal maturation of brain and behavior can result in cognitive impairments and in lasting changes of emotionality, as has been reported in humans after parental deprivation, severe stress, and juvenile traumatic experiences.

\section{ACKNOWLEDGMENTS}

The authors wish to thank P. Kremz for her excellent technical assistance. This research was supported by a grant from the German Science Foundation SFB 426 and from the Ministry of Sachsen-Anhalt LSA 3201A/0020G.

\section{REFERENCES}

Akinci MK, Johnston GA. Sex differences in acute swim stress-induced changes in the binding of MK-801 to the NMDA subclass of glutamate receptors in moue forebrain. J Neurochem 1993; 61: 2290-2293.

Bartanusz V, Aubry JM, Pagliusi S, Jezova D, Baffi $\mathrm{J}$, Kiss JZ. Stress-induced changes in messenger RNA levels of N-methyl-D-aspartate and AMPA receptor subunits in selected regions of the rat hippocampus and hypothalamus. Neuroscience 1995; 66:247-252.

Blandini F, Porter RH, Greenamyre JT. Glutamate and Parkinson's disease. Mol Neurobiol 1996; 12; 73-94.

Bock J, Wolf A, Braun K. Influence of the N-methylD-aspartate receptor antagonist DL-2-amino-5phosphono valeric acid on auditory filial imprinting in the domestic chick. Neurobiol Learn Mem 1996; 65: 177-188.

Bock J, Schnabel R, Braun K. The role of the dorsocaudal neostriatum in filial imprinting of the domestic chick: A pharmacological and autoradiographical approach focused on the involvement of NMDAreceptors. Eur J Neurosci 1997; 9: 1262-1272.

Bock J, Braun K. Blockade of N-methyl-D-aspartate receptor activation suppresses learning-induced synaptic elimination. Proc Natl Acad Sci USA 1999; 96: 2485-2490.

Braun K, Lange E, Metzger M, Poeggel G. Parental separation followed by early social deprivation affects the development of monoaminergic fiber systems in the medial prefrontal cortex of Octodon degus. Neuroscience 2000; 95: 309-138.

Braun S, Scheich $\mathrm{H}$. Influence of experience on the representation of the "mothering call" in frontoparietal and auditory cortex of pups of the rodent Octodon degus: FDG mapping. J Comp Physiol 1997; 181: 697-709. 
De Casper AJ, Fifer WP. Of human bonding: Newborns prefer their mothers' voices. Science 1980; 208: 1174-1176.

Doherty MD, Gratton A. NMDA receptors in nucleus accumbens modulate stress-induced dopamine release in nucleus accumbens and ventral tegmental area. Synapse 1997; 26: 225-234.

Fifer WP, Moon Committee. The role of the mother's voice in the organization of brain function in the newborn. Acta Pediatr 1994; 397(Suppl): 86-93.

Flood JF, Morley JE. Learning and memory in the SAMP8 mouse. Neurosci Biobehav Rev 1998; 22: 1-20.

Folbergrova J, Haugvicova R, Mares P. Behavioral and metabolic changes in immature rats during seizures induced by homocysteic acid: the protective effect of NMDA and non-NMDA receptor antagonists. Exp Neurol 2000; 161: 336-345.

Fulk W. Notes on the activity, reproduction and social behavior of Octodon degus. 1976.

Guitierrez H, Hernandez-Echeagaray E, Ramirez-Amaya V, Bermudez-Rattoni F. Blockade of N-methyl-Daspartate receptors in the insular cortex disrupts taste aversion and spatial memory formation. Neuroscience 1999; 89: 751-758.

Gray PH. Theory and evidence of imprinting in human infants. J Psychol 1958; 46: 155-166.

Hall FS. Social deprivation of neonatal, adolescent, and adult rats has distinct neurochemical and behavioral consequences. Crit Rev Neurobiol 1998; 12: 129-162.

Hattori H, Wasterlain CG. Excitatory amino acids in the developing brain: ontogeny, plasticity, and excitotoxicity. Pediatr Neurol 1990; 6: 219-228.

Izquierdo I, Medina JH. Memory formation: The sequence of biochemical events in the hippocampus and its connection to activity in other brain structures. Neurobiol Learn Mem 1997; 68: 285-316.

Jedema HP, Moghaddam B. Glutamatergic control of dopamine release during stress in the rat prefrontal cortex. J Neurochem 1994; 63: 785-788.

Jezova D, Jurankova E, Vigas M. Glutamate neurotransmisson, stress and hormone secretion. Bratisl Lek Listy 1995; 96: 588-956.

Jones GH, Hernandez TD, Kendall DA, Marsden CA, Robbins TW. Dopaminergic and serotonergic function following isolation-rearing in rats: A study of behavioral responses and postmortem and in vivo neurochemistry. Pharmacol Biochem Behav 1992; 431: 17-35.
Kehne JH, McCloskey TC, Baron BM, Chi EM, Harrison BL, Whitten JP, Palfreyman MG. NMDA receptor complex antagonists have potential anxiolytic effects as measured with separation-induced ultrasonic vocalizations. Eur J Pharmacol 1991; 14; 193: 283-292.

Krugers HJ, Koolhaa JM, Bohus B, Korf J. A single social stress-experience alters glutamate receptor binding in rat hippocampal CA3 area. Neurosci Lett 1993; 14: 73-77.

Liljequist R, Henriksson BG, Latif N, Pham T, Winblad B, Mohammed AH. Subchronic MK-801 treatment to juvenile rats attenuates environmental effects on adult spatial learning. Behav Brain Res 1993; 56: 107-114.

Liu D, Caldji C, Sharma S, Plotsky PM, Meaney MJ. Influence of neonatal rearing conditions on stressinduced adrenocorticotropin responses and norepinepherine release in the hypothalamic paraventricular nucleus. J Neuroendocrinol 2000; 12: 512.

McEwen BS. Stress and hippocampal plasticity. Annu Rev Neurosci 1999; 22: 105-122.

McEwen BS, Magarinos AM. Stress effects on morphology and function of the hippocampus. Annals NY Acad Sci 1997; 821: 271-284.

Mikuni N, Babb TL, Ying Z, Najm I, Nishiyama K, Wylie C, et al. NMDA-receptors 1 and 2A/B coassembly increased in human epileptic focal cortical dysplasia. Epilepsia 1999; 40: 1683-1687.

Musshoff U, Schunke U, Kohling R, Speckman EJ. Alternative splicing of the NMDAR1 glutamate receptor subunit in human temporal lobe epilepsy. Brain Res Mol Brain Res 2000; 29; 76: 377-384.

Olney JW, Farber NB. Glutamate receptor dysfunction and schizophrenia. Arch Gen Psychiatry 1995; 52: 998-1007.

Olney JW, Newcomer JW, Farber NB. NMDA receptor hypofunction model of schizophrenia. J Psychiatr Res 1999; 33: 523-533.

Poeggel G, Braun K. Early auditory filial learning in degus (Octodon degus): behavioral and autoradiographic studies. Brain Res 1996; 743: 162-170.

Poeggel G, Lange E, Haase C, Metzger M, Gulyaeva N, Braun K. Parental separation and early social deprivation in Octodon degus: Quantitative changes of nicotinamide adenine dinucleotide phosphatediaphorase-reactive neurons in the prefrontal cortex and nucleus accumbens. Neuroscience 1999; 94: 497-504. 
Poeggel G, Haase C, Gulyaeva N, Braun K. Quantitative changes in reduced nicotinamide adenine dinucleotide phosphate-diaphorase-reactive neurons in the brain of Octodon degus after periodic parental separation and early social isolation. Neuroscience 2000; 99: 381-387.

Roullet P, Bourne R, Moricard Y, Stewart MG, Sara SJ. Learning-induced plasticity of N-methyl-Daspartate receptors is task and region specific. Neuroscience 1999; 89: 1145-1150.

Schnabel R, Braun K. Development of dopamine receptors in the forebrain of the domestic chick in relation to auditory imprinting. An autoradiographic study. Brain Res 1996; 720: 120-130.

Schwendt M, Jezova D. Gene expression of two glutamate receptor subunits in response to repeated stress exposure in rat hippocampus. Ell Mol Neurobiol 2000; 20: 319-329.

Shors TJ, Mathew PR. NMDA receptor antagonism in the lateral/basolateral but not central nucleus of the amygdala prevents the induction of facilitated learning in response to stress. Learn Mem 1998; 5: 220-230.

Skeels HM. Adult status of children with contrasting early life experiences: A follow-up study. Monographs of the Society for Research in Child Development 1966; Serial No. 105, Vol. 31.

Spitz RA. Hospitalism. Psychoanalytical study of the child 1945; 1: 53-74.

Gray PH. Theory and evidence of imprinting in human infants. J Psychol 1958; 46: 155-166.

Staubli UV. Parallel properties of long-term potentiation and memory. In: McGaugh JL, Weinberger NM, Lynch G, eds, Brain and Memory Modulation and Mediation of Neuroplasticity. New York, NY,
USA: Oxford UP 1995; 303-318.

Suomi, SJ. Early stress and adult emotional reactivity in rhesus monkeys. Proceedings, The Childhood Environment and Adult Disease. Chichester, UK: Ciba Foundation Symp. 156, 1991; 171-188.

Takahata R, Moghaddam B. Glutamatergic regulation of basal and stimulus-activated dopamine release in the prefrontal cortex. J Neurochem 1998; 71: 1443-1449.

Thoa NB, Tizabi Y, Jacobowitz DM. The effect of prolonged isolation on the catecholamine and serotonin concentration of discrete areas of the rat brain. In: Catecholamines and Stress. Oxford, UK: Pergamon Press 1976.

Tocco G, Shors TJ, Baudry M, Thompson RF. Selective increase of AMPA binding to the AMPA/quisqualate receptor in the hippocampus in response to acute stress. Brain Res 1991; 13: 168-171.

Weinstock M, Speiser Z, Ashkenazi R. Changes in brain catecholamine turnover and receptor sensitivity induced by social deprivation in rats. Psychopharmacology 1978; 102: 364-375.

Wilson S. Contact-promoting behavior, social development, and relationship with parents in sibling juvenile degus (Octodon degus). Dev Psychobiol 1982; 15: 257-268.

Zigmond MJ, Castro SL, Keefe KA, Abercrombie ED, Sved AF. Role of excitatory amino acids in the regulation of dopamine synthesis and release in the neostriatum. Amino Acids 1998; 14: 57-62.

Zelena D, Makara GB, Jezova D. Simultaneous blockade of two glutamate receptor subtypes (NMDA and AMPA) results in stressor-specific inhibition of prolactin and corticotropin release. Neuroendocrinology 1999; 69: 316-323. 

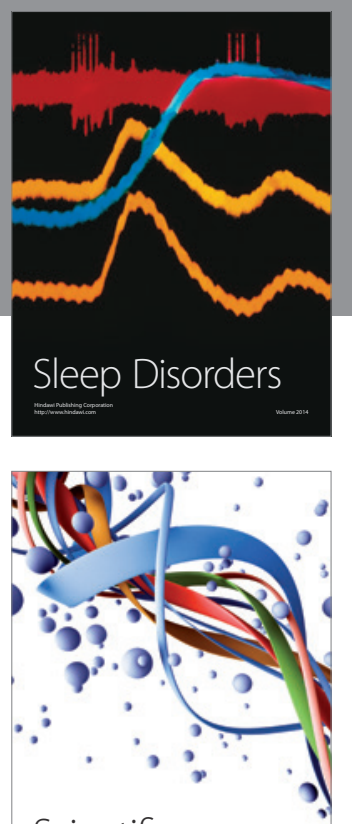

Scientifica
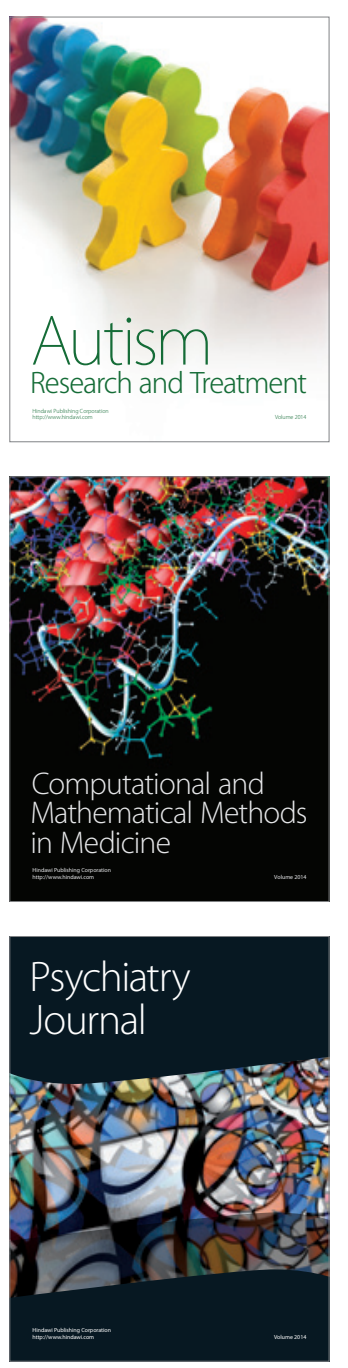
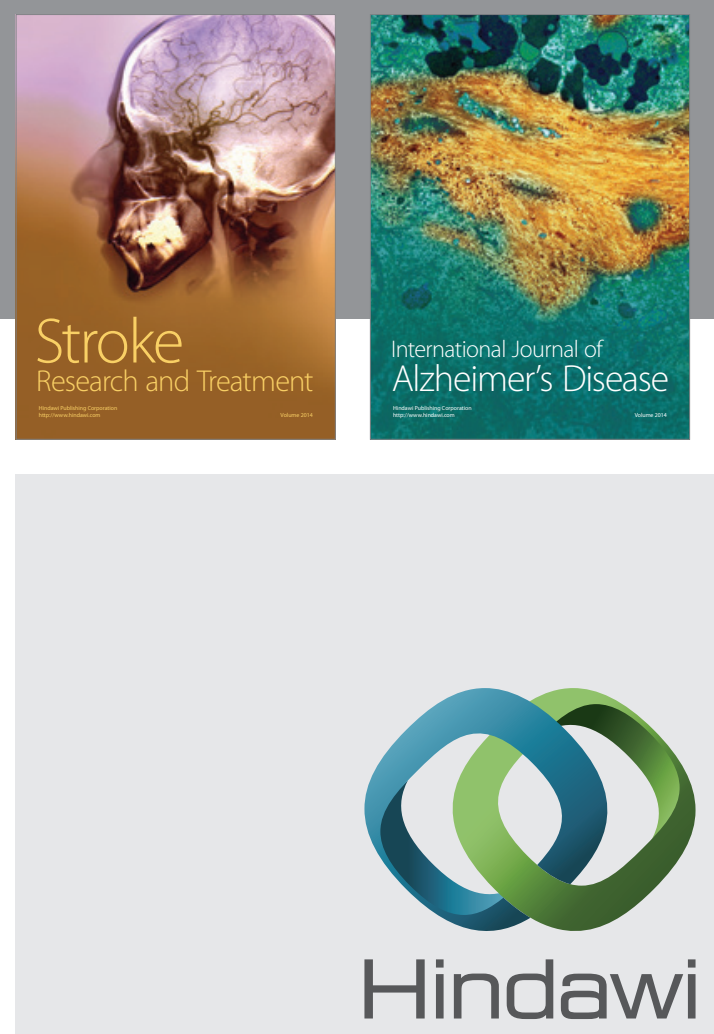

Submit your manuscripts at

http://www.hindawi.com
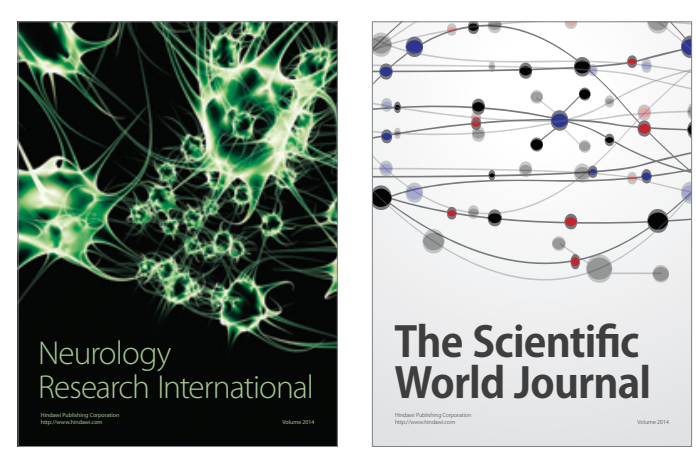

The Scientific World Journal

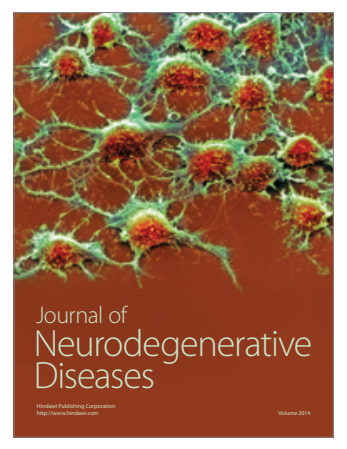

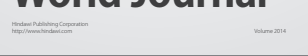

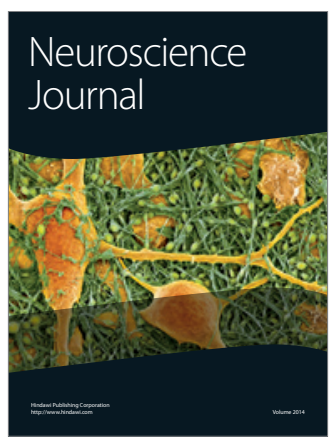

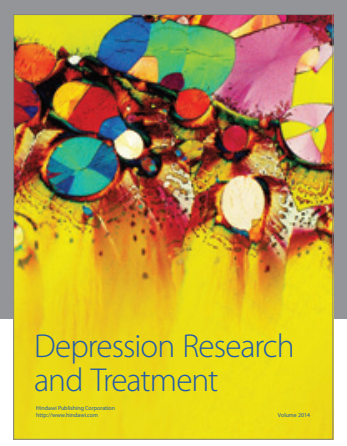
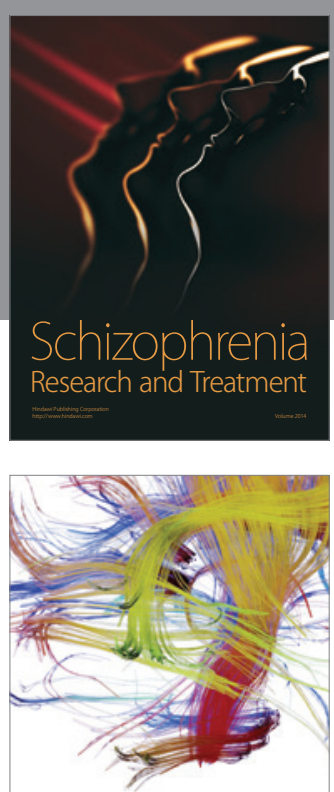

Brain Science

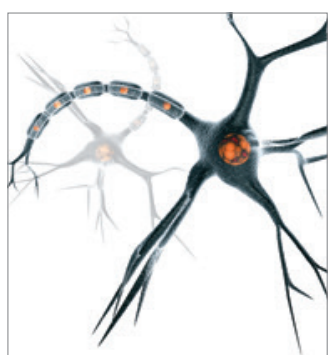

Neural Plasticity
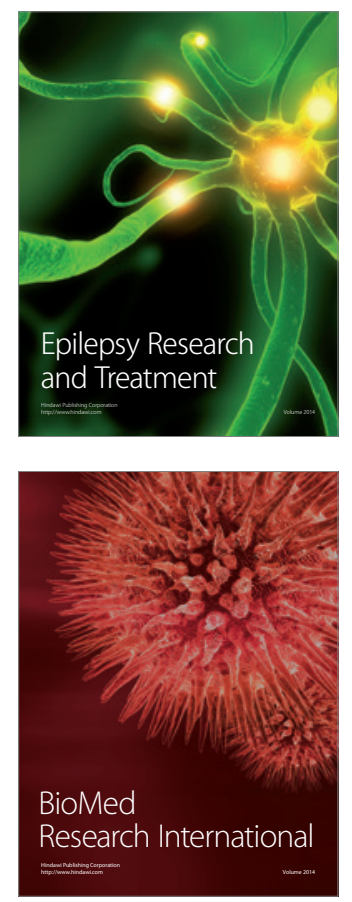

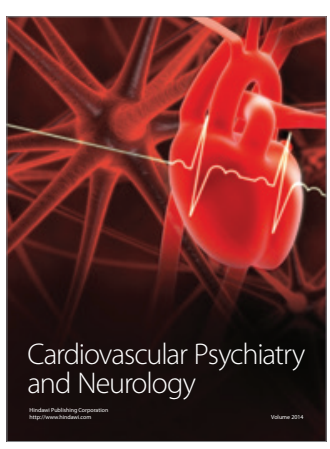

Parkinson's

Disease
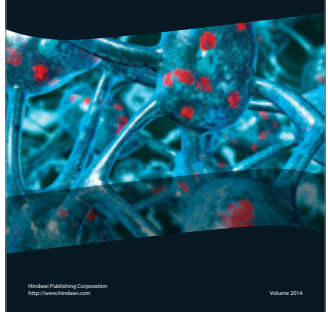